\title{
Regra do pico-fim e negligência com relação ao tempo: evidências de um experimento com hóspedes de um resort de praia
}

Peak-end rule and duration neglect: Evidence from an experiment with guests at a seaside resort

\begin{abstract}
The purpose of this study is to observe whether the peak-end rule and duration neglect are checked on guests of a leisure hotel, examining whether clients demonstrate the biases found in the behavioral economics literature. The experiment was conducted with 39 guests from a resort located in Florianopolis, Brazil, during the summer and fall of 2015. The main results revealed that peak-end rule is not fully confirmed, since only the peak was shown to be significant in determining overall satisfaction. Regarding the negligence with respect to time, it is confirmed that the duration of the event has no correlation with this final evaluation.
\end{abstract}

\section{Keywords}

peak-end rule, duration neglect, behavioral economics, field experiment.

JEL Codes D91.

\author{
Guilherme Faria Alano (1) \\ Newton Carneiro Affonso Da Costa Junior (2) \\ Jéssica Pulino Campara ${ }^{(3)}$ \\ (1) Universidade Federal de Santa Catarina \\ (2) Pontifícia Universidade Católica do Paraná \\ ${ }^{(3)}$ Universidade Federal de Santa Catarina
}

\section{Resumo}

O objetivo deste estudo consiste em observar se a regra do pico-fim e da negligência com relação ao tempo é verificada em hóspedes de um hotel de lazer, examinando se os clientes demonstram os vieses encontrados na literatura de economia comportamental. $O$ experimento foi realizado com 39 hóspedes de um resort localizado em Florianópolis, Brasil, durante o verão e outono de 2015. Os principais resultados revelam que a regra do pico-fim não é confirmada completamente, já que apenas o pico mostrou-se significativo para determinar a satisfação geral. Em relação à negligência com relação ao tempo, confirma-se que a duração do evento não tem correlação com essa avaliação final.

\section{Palavras-chave}

regra do pico-fim, negligência com relação ao tempo, economia comportamental, experimento de campo.

Códigos JEL D91. 


\section{Introdução}

A economia e as finanças comportamentais seguiram a revolução comportamental na psicologia que, nos anos de 1970, começou a estudar como as pessoas tomam decisões ao se defrontarem com diversas alternativas de risco, como dependem de heurísticas para formar seus juízos e como são vulneráveis a vieses. Os grandes idealizadores dessa abordagem foram os psicólogos Kahneman e Tversky (1979), que desenvolveram a teoria do prospecto, vista como basilar para a economia e as finanças comportamentais.

Partindo dessa primeira constatação, ao longo das décadas seguintes, diversos autores identificaram diferentes vieses comportamentais. Entre estes, destacam-se as investigações acerca do processo de avaliação retrospectiva de eventos, realizada inicialmente por Kent (1985), Rachman e Eyrl (1989) e Thomas e Diener (1990), e formalizada por Kahneman et al. (1993), os quais conseguiram sintetizar esse processo em um experimento de laboratório captando todas as características do processo, servindo assim como base para os experimentos subsequentes. As conclusões desses estudos elucidaram que a avaliação retrospectiva de eventos pode ser subdividida em dois desvios cognitivos: regra do pico-fim (peak-end rule) e negligência com relação ao tempo (duration neglect), as quais fogem não só da racionalidade esperada do agente econômico padrão, que tem como base a teoria da utilidade esperada, como também produz a possibilidade de manipular as sensações do indivíduo para produzir um resultado diferente daquele que seria alcançado, apenas mudando a disposição de como transcorre o evento.

Segundo as demonstrações até então apresentadas, os indivíduos seriam mais sensíveis na avaliação retrospectiva, em termos de sua intensidade de pico e fim, ou seja, a busca na memória, como um processo de julgamento, dá maior ênfase a esses dois momentos (sensação média do pico de satisfação e do momento imediatamente anterior ao fim da experiência) (Fredrickson, 2000). Essa constatação leva naturalmente a um segundo padrão: o tempo decorrido não é um fator relevante nessa avaliação. Fredrickson e Kahneman (1993) ressaltam que essa negligência não implica que a informação da duração é perdida e nem mesmo que as pessoas acreditem que a duração de um evento não é um fator importante, mas o que fica mais relevante na avaliação retrospectiva são os momentos mais marcantes e aquele imediatamente ao fim da experiência, ficando o tempo em segundo plano. 
Tendo por base essa teoria, este trabalho tem como objetivo observar se a regra do pico-fim e a negligência com relação ao tempo são verificadas em hóspedes de um resort na cidade de Florianópolis, Brasil. Como objetivos específicos destacam-se: a) analisar a percepção dos hóspedes relativamente às perguntas desenvolvidas; b) verificar se a regra do pico-fim momentâneo é um bom previsor da avaliação retrospectiva de um evento; c) verificar se o tempo de permanência no hotel, ou duração do evento, tem correlação com a avaliação geral do período; e d) testar a regra do pico-fim e da negligência em relação ao tempo.

Como justificativas para o estudo, destaca-se inicialmente a incipiência de pesquisas a respeito do tema, principalmente em contexto brasileiro e, na literatura internacional, a carência de estudos relacionados a ambientes reais (field experiment), como o de um resort. Além disso, investigar a avaliação retrospectiva dos indivíduos é relevante, no sentido que esse comportamento pode gerar diversas implicações práticas, o que indica que há espaço para explorar os seus efeitos e documentar o reflexo dessas anomalias em diversos campos de estudo. Ariely e Carmon (2003) apontam essas implicações, relatando que avaliações retrospectivas de dor ou prazer de um evento são, obviamente, importantes informações utilizadas no processo de decisão; que positivamente ou negativamente as pessoas relembrarem de uma experiência é um fator-chave para saber se elas vão procurar novamente essa atividade ou se recomendariam isso para outras pessoas; e por fim enfatiza que entender o processo de avaliação retrospectiva pode determinar como as pessoas "consomem" essa memória.

Como contribuições do estudo aponta-se que a investigação das hipóteses da regra do pico-fim e da negligência com relação ao tempo neste experimento pode trazer uma melhor abordagem para a área de economia comportamental, ensejando estudos que melhorem a compreensão das decisões individuais, baseados em avaliações retrospectivas de experiências semelhantes. Além disso, pode produzir conhecimento para outras áreas relacionadas à psicologia e economia - como o marketing -, priorizando ações que melhorem a experiência do seu público consumidor para a parte final dessa interação, e principalmente melhor compreensão do processo de avaliação retrospectiva de eventos feitos pelo ser humano.

Nesse sentido, este trabalho toma relevância na literatura, por transcorrer em ambiente natural e sem nenhum tipo de interferência do pesquisador que pudesse significar um viés de decisão (exceto, evidentemente, o 
estímulo final auferido por uma parte da amostra a fim de verificar sua significância). Ressalta-se ainda que este é o primeiro trabalho experimental no Brasil, documentado em um ambiente de economia real, a investigar os vieses sintetizados na "regra do pico-fim" e da negligência com relação ao tempo, pavimentando o espaço para que outros trabalhos busquem ratificar ainda mais esse tipo de comportamento e/ou utilização desse padrão de comportamento para a promoção de programas públicos ou privados que visem à melhora do bem-estar e da satisfação dos indivíduos.

\section{Referencial teórico}

Investigar a tomada de decisão dos indivíduos é um processo complexo, dado que este é fortemente influenciado por fatores que levam ao desvio da racionalidade, seja por emoções, fatores químicos, psíquicos ou ambientais, que pode desencadear decisões enviesadas. Foi verificando esse contexto que Amos Tversky e Daniel Kahneman contribuíram significativamente para a compreensão do comportamento humano. Entre essas contribuições, Kahneman (2012, p. 476) discorreu sobre os "dois eus": o eu experiencial, que responde à pergunta: "Está doendo agora?" e o eu recordativo, que responde à pergunta: "Como foi isso no todo?". Com essa diferenciação, Kahneman avança, pois enquanto outros estudiosos desenvolveram o conceito de "eu" múltiplo ou "dinâmico", Kahneman evidencia os dois "eus" (experiencial e recordativo), indicando que esses agem de maneira distinta, considerando as noções de utilidade (Zajchowski; Schwab; Dustin, 2017).

Nesse sentido, Kahneman (2012) subdividiu o conceito de utilidade em dois âmbitos: a utilidade experimentada e a utilidade de decisão. A primeira diz respeito às memórias (eu recordativo), algo já vivenciado, e a segunda significa "desejabilidade". A teoria da utilidade experimentada refere-se às regras de racionalidade que devem definir a utilidade de decisão, ou seja, a utilidade experimentada deve ser o critério pelo qual uma decisão deve ser avaliada (Kahneman, 2012). Assim, quando a utilidade de decisão não corresponde à utilidade experimentada algo de errado está acontecendo.

Diversos trabalhos revelaram que essa inconsistência na decisão acontece de maneira sistemática entre os seres humanos, e diversos padrões de irracionalidade, que posteriormente puderam ser incorporados no contex- 
to das ciências econômicas, foram documentados. Alguns desses trabalhos mostraram que a avaliação de experiências recentes não é racional e infringe uma lógica básica da psicologia, o princípio da "monotonicidade temporal", segundo o qual acrescentar momentos de dor ou de desconforto a um episódio só pode torná-lo pior e, analogamente, acrescentar momentos de prazer a um episódio só pode torná-lo melhor. Portanto, se um indivíduo se mostra indiferente a duas opções distintas, necessariamente, se acrescentar um momento de dor ou desconforto a uma dessas situações, esta passa a ser preterida pela outra opção.

Redelmeier, Katz e Kahneman (2003) ilustram bem essa situação a partir de um estudo com pacientes submetidos a um procedimento clínico doloroso (colonoscopia). Nele, os pesquisadores pediam para que os participantes avaliassem o nível de desconforto que estavam sentindo durante o procedimento a cada 60 segundos, variando do nível 0, dor nenhuma, até o nível 10, dor intolerável. O gráfico (Figura 1) de dois pacientes ilustra o relatório de dor reportado por eles.

Figura 1 Relatório de dor dos pacientes "A" e "B" submetidos ao exame de colonoscopia
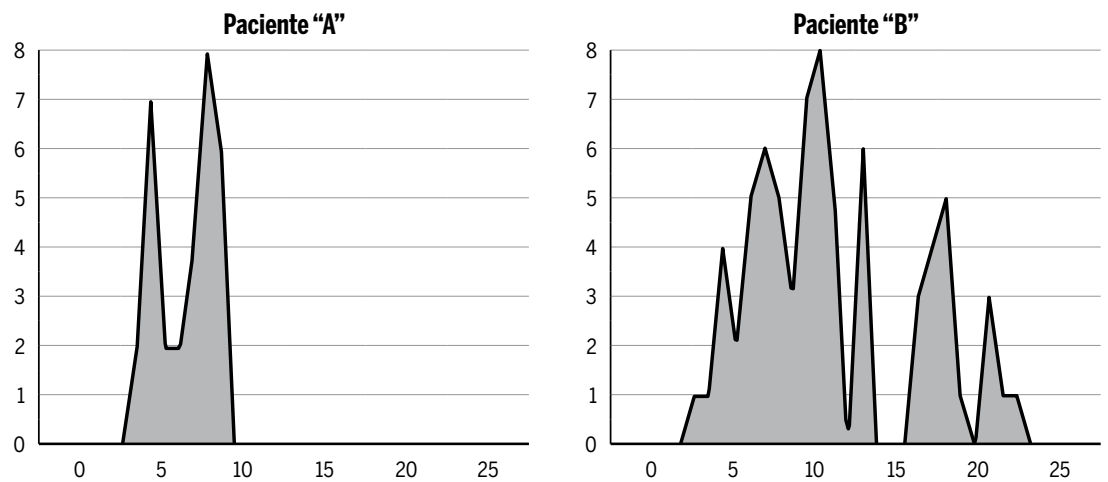

Fonte: Redelmeier; Katz; Kahneman, 2003.

Embora o paciente A tenha tido uma experiência dolorosa bem mais curta do que o paciente $B$, quando requisitados para fazer uma avaliação retrospectiva geral do procedimento, o paciente A relatou que "a quantidade total de dor" vivenciada foi maior que a avaliação do paciente B. Esse resultado foi corroborado por outros experimentos semelhantes em que se encontraram dois fenômenos padrão. $O$ primeiro foi o que os autores denominaram de regra do pico-fim (peak-end rule), em que a avaliação da 
experiência retrospectiva foi melhor prevista por uma média entre o pico mais alto de dor sentida e pelo nível de dor sentido no momento imediatamente anterior ao fim do procedimento. A segunda constatação foi a negligência com a duração temporal (duration neglect), na qual a duração total do procedimento não teve correlação com a avaliação total da dor retrospectivamente.

Esse resultado foi testado em outros experimentos similares, tanto em laboratórios como em situações reais (Christman; Propper; Brown, 2008). Bem como, testada em ambientes não de dor e desconforto, mas em experimentos onde os participantes eram submetidos a sensações de prazer e satisfação, e em situações com ambas as sensações, prazer e desconforto dentro de um mesmo experimento. Kahneman et al. (1993), por exemplo, realizaram um experimento pioneiro no qual os participantes foram expostos a situações de dor e desconforto. $\mathrm{O}$ indivíduo era convidado a imergir uma das duas mãos durante 60 segundos em um recipiente com água controlada em $14^{\circ} \mathrm{C}$, relatando a todo o momento o nível de dor sentido. Num segundo momento, o mesmo indivíduo imergia a mão oposta à utilizada no primeiro teste e, sem serem informados, os pesquisadores acrescentavam 30 segundos a mais com a mão imersa e durante esse tempo adicional a água era aquecida a $15^{\circ} \mathrm{C}$. Após os dois testes, os participantes do experimento respondiam a um questionário com as impressões dos dois testes, entre as quais perguntava : se fosse necessário realizar o experimento novamente, com qual das duas mãos eles preferiam repetir. A maior parte dos participantes avaliou ser menos desconfortável o teste dos 90 segundos e, consequentemente, preferia repetir o experimento mais demorado, embora tenha relatado um total de dor maior durante o experimento do que no teste de 60 segundos.

Seguindo a mesma lógica do experimento da mão na água gelada, Kemp, Burt e Furneaux (2008) avaliariam se esse padrão psicológico existiria numa amostra de estudantes em férias, sendo submetidos a sensações de prazer ao invés de dor. Os participantes do experimento relatavam diariamente, através de mensagem de texto para celular, os níveis de prazer e felicidade diários. Embora a negligência relativa ao tempo tenha sido observada, ou seja, não foi constatada correlação entre o período de férias e o total de felicidade relatado, a regra do pico-fim não foi um bom previsor como em outros experimentos, provavelmente porque não houve nenhum incentivo exógeno que produzisse uma modificação na avaliação 
imediatamente anterior ao fim do experimento para que ficasse exposto o possível efeito da regra do pico-fim, podendo, assim, ter passado despercebido pelos pesquisadores.

É neste ponto que se destaca uma possível dificuldade nesse tipo de experimento, conseguir produzir na parte final do procedimento uma sensação que gere felicidade ao indivíduo, principalmente em experimentos feitos fora de laboratório. Para solucionar esse empasse, Do, Rupert e Wolford (2008) exploraram a regra do pico-fim com um incentivo que tornasse a avaliação imediatamente anterior ao fim do evento mais prazerosa através de dois experimentos. No experimento 1, os estudantes que haviam feito uma doação através de uma campanha para uma instituição de caridade estariam participando de uma rifa que sortearia DVDs, mas todos foram sorteados, havendo uma lista "A", com filmes considerados excelentes, e uma lista "B", com filmes razoáveis. Os participantes que receberam a lista " $\mathrm{B}$ " e, posteriormente, a lista "A" de filmes para escolher avaliaram terem se sentido mais contentes (média 4,82) com o prêmio do que os indivíduos que receberam a lista " $\mathrm{A}$ " e, posteriormente, a lista "B" de filmes (média 4,14). Alguns participantes receberam somente um prêmio com um DVD de cada uma das listas. Os que receberam da lista "A" avaliaram o prêmio significativamente melhor (média 5,21) do que os que receberam da lista de filmes "B" (média 2,57). Esse experimento revela também a versão análoga do experimento de Kahneman et al. (1993) em que mais dor foi preferível a menos dor, já que, embora avaliassem positivamente receber um DVD da lista "B", os indivíduos que receberam somente um único DVD proveniente da lista "A" relataram um nível de contentamento maior (média 5,21 ) do que os que receberam dois DVDs, independentemente da ordem de recebimento, ou seja, a soma de mais um evento que individualmente tenha sido classificado como prazeroso afeta negativamente a avaliação retrospectiva do evento.

Como descrito em vários artigos sobre o tema, esse fenômeno torna possível, para empresas em geral, uma nova abordagem para seus clientes, utilizando essa deficiência na avaliação retrospectiva para alavancar vendas, fidelizar clientes e, de uma maneira geral, aumentar a satisfação dos seus consumidores. Para Stratten e Kramer (2014), lidar com essa informação pode ser um aspecto muito importante para os negócios, pois as pessoas podem voltar a um estabelecimento pelo marketing, mas voltarão principalmente pelas experiências que têm na memória de quando estiveram no lugar. 
Esse arcabouço teórico é ratificado pelos estudos de memorização que indicam haver nesse processo características estáticas, refletindo a intensidade momentânea da experiência, e uma característica dinâmica, que reflete a mudança de intensidade das diferentes sensações sentidas no decorrer de um evento, ambas dando forte subsídio à regra do pico-fim (Ariely; Carmon, 2003). As evidências das características estáticas indicam que no processo de lembrança do evento alguns pontos importantes são armazenados para posterior uso, e não o processo como um todo. Como na metáfora de Kundera (1991), a memória é mais como um armazenamento de fotografias, e não de um filme. Sendo assim, além da memorização de algumas poucas lembranças, e não do processo inteiro, a dinâmica dos eventos também é relevante. Os autores encontraram suporte de que eventos que tiveram aumento de intensidade ao longo do processo, sejam eles negativos ou positivos, têm efeito significativo na avaliação retrospectiva total. Mesmo eventos não monotônicos, em que ao longo do processo houve uma inversão da tendência, os resultados foram melhores previstos não pela soma total, mas sim por uma avaliação ponderada de todos os relatos ao longo do evento.

\section{Método}

Para o desenvolvimento do estudo realizou-se um experimento natural ou quase-experimento, sendo os participantes submetidos ao ambiente natural, sem influência do pesquisador. Classifica-se também como experimento de campo, dado que ocorreu num ambiente real, sujeito a todas as intempéries naturais, fora do controle do pesquisador (List, 2006).

Como público do experimento tem-se os hóspedes de um resort de praia na cidade de Florianópolis, Estado de Santa Catarina, Brasil. O contato com os possíveis participantes da pesquisa foi realizado, primeiramente, no ato do check-in no hotel. Os hóspedes eram abordados e questionados se poderiam responder às perguntas diárias, ficando livres ou para recusar ou para desistir a qualquer momento, caso aceitassem respondê-las. No caso de aceite do hóspede, este passava um número de telefone para que fossem enviadas as perguntas. No entanto, esse processo de abordagem durante o check-in dos hóspedes no hotel não se mostrou eficiente, sendo alterada para a Central de Hóspedes. Essa mudança facilitou o contato com os hóspedes, na medida em que estes já se encontravam mais descan- 
sados e dispostos a autorizar a participação no experimento. Ressalta-se que no momento da abordagem os pesquisadores colhiam a assinatura de aceitação de participação no experimento, mas não era informado a que se destinava o experimento, nem as perguntas que seriam feitas.

A coleta dos dados se deu no período de verão e outono de 2015 e contemplou uma amostra de 39 hóspedes do hotel, sendo que 11 não responderam em algum momento do experimento, ou o fizeram em atraso, os quais tiveram de ser descartados. Além dessas exclusões, optou-se por eliminar as respostas concedidas por um hóspede solteiro, já que todos os outros eram casais, totalizando, assim, 27 participantes. Diariamente, na parte final do dia, por volta das 18 horas, esses hóspedes eram contatados pelos pesquisadores através de mensagem de texto para celular. Nessas mensagens de texto, eram realizadas três perguntas a serem respondidas numa escala de 1 a 10, conforme abaixo:

- Pergunta 1) Por favor, classifique como você se sente nesse momento?

Entre: 1 (extremamente infeliz) e 10 (extremamente feliz);

- Pergunta 2) Em média, nas últimas 24 horas, como você se sentiu?

Entre: 1 (extremamente infeliz) e 10 (extremamente feliz);

- Pergunta 3) Por favor, classifique como você se sentiu no melhor momento desde a última verificação.

Entre: 1 (extremamente infeliz) e 10 (extremamente feliz).

Cinco dias após o check-out no hotel, o cliente recebia uma nova mensagem de texto, a fim de colher a última avaliação do evento. Ressalta-se que se optou por cinco dias posteriores ao check-out, pois segundo Geng et al. (2013) existe um problema com o período em que o pico e o final das experiências podem ser acessados pelas memórias, porque estas ao longo do tempo podem ir diminuindo, assim realizar essa investigação um longo período após a experiência poderia não gerar resultados fidedignos ao experimento. A mensagem encaminhada continha o seguinte conteúdo:

- A fim de completar o questionário referente à sua estadia no hotel, por favor, responda somente com números.

Exemplo de resposta: $6-7$.

- Pergunta 4) Como você classifica seu período de hospedagem no hotel?

Entre: 1 (extremamente infeliz) e 10 (extremamente feliz); 


\section{- Pergunta 5) Classifique como você se sente neste momento?}

Entre: 1 (extremamente infeliz) e 10 (extremamente feliz).

Os dados recebidos foram sendo compilados em banco de dados para posterior análise. A análise dos dados foi realizada utilizando metodologia proposta Kemp, Burt e Furneaux (2008), os quais embasaram o questionário aplicado no presente estudo. A mensuração da regra do pico-fim foi calculada da seguinte maneira:

(1)Pico-fim momentâneo (a média da avaliação de felicidade relatada no momento mais alto - maior avaliação da pergunta 1) e da avaliação no último dia (resposta da pergunta 1 no último dia);

Para análise dos dados foram realizadas as seguintes etapas: estatística descritiva, correlação de Pearson e regressão linear. Por meio da estatística descritiva foi possível investigar a percepção dos hóspedes com relação a todas as avaliações realizadas. A correlação permitiu verificar a associação entre o pico-fim momentâneo e a satisfação final com a hospedagem. Já a regressão oportunizou investigar se o pico, o fim e o tempo impactam na satisfação geral.

\section{Análise e discussão dos resultados}

Da amostra investigada, 12 hóspedes entrevistados eram casais sem filhos e 15 casais com filhos. Todos os participantes possuíam nacionalidade brasileira, divididos na sua maioria em hóspedes provenientes do Paraná (14), Santa Catarina (8), Rio Grande do Sul (2), Goiás (2), São Paulo (1) Rio de Janeiro (1). As respostas dos hóspedes para cada uma das perguntas estão compiladas na Tabela 1.

Por meio desses resultados iniciais é possível destacar de antemão que os hóspedes possuem uma boa avaliação em relação ao período de estadia. Nenhum dos participantes do experimento avaliou a experiência passada no hotel (pergunta 4) como pior do que como se sentia no momento (pergunta 5). Dos 27 participantes que responderam a todas as questões solicitadas, 10 se sentiam tão felizes no momento da resposta quanto no período de permanência no hotel, e 18 participantes avaliaram melhor o período de estadia. 
Tabela 1 Resumo de todas as respostas do experimento

\begin{tabular}{|c|c|c|c|c|c|c|c|c|c|c|c|}
\hline 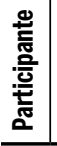 & $\begin{array}{r}\text { Dia } \\
1\end{array}$ & $\begin{array}{r}\text { Dia } \\
2\end{array}$ & $\begin{array}{r}\text { Dia } \\
3\end{array}$ & $\begin{array}{r}\text { Dia } \\
4\end{array}$ & $\begin{array}{r}\text { Dia } \\
5\end{array}$ & $\begin{array}{r}\text { Dia } \\
6\end{array}$ & $\begin{array}{r}\text { Dia } \\
7\end{array}$ & $\begin{array}{r}\text { Dia } \\
8\end{array}$ & $\begin{array}{r}\text { Dia } \\
9\end{array}$ & $\begin{array}{r}\text { Dia } \\
10\end{array}$ & Final \\
\hline 1 & $6-5-10$ & 5-7-10 & 7-5-10 & $8-8-10$ & 8-8-10 & & & & & & $8-6$ \\
\hline 2 & 8-8-9 & 8-9-9 & 9-9-9 & $9-9-9$ & $9-9-9$ & & & & & & $9-8$ \\
\hline 3 & 7-7-8 & 6-8-8 & 6-6-6 & 7-6-7 & & & & & & & $7-7$ \\
\hline 4 & $8-8-8$ & $8-8-8$ & $7-8-9$ & 6-6-6 & $7-8-7$ & $9-9-9$ & $8-9-7$ & $8-8-7$ & & & $8-8$ \\
\hline 5 & $10-10-10$ & $9-9-10$ & 9-9-10 & $10-9-8$ & $10-10-10$ & $9-9-9$ & 8-9-8 & $8-8-8$ & $9-9-9$ & $8-9-8$ & $10-6$ \\
\hline 6 & $9-8-9$ & $10-9-9$ & $9-9-8$ & 8-8-8 & $9-8-8$ & $9-9-8$ & & & & & $9-7$ \\
\hline 7 & 6-8-10 & $9-9-8$ & $9-9-7$ & $9-9-8$ & 8-8-7 & $8-8-7$ & & & & & $7-7$ \\
\hline 8 & $9-9-9$ & $9-9-9$ & $9-9-9$ & $9-9-10$ & $9-9-8$ & & & & & & $9-7$ \\
\hline 9 & 8-7-7 & $9-9-7$ & $10-9-8$ & 7-7-8 & $7-8-8$ & $9-8-8$ & & & & & $9-8$ \\
\hline 10 & 7-7-7 & $7-8-7$ & 8-7-7 & $9-8-8$ & $7-9-8$ & $7-7-8$ & $7-8-7$ & & & & $8-8$ \\
\hline 11 & $7-6-6$ & 7-7-7 & $8-8-7$ & & & & & & & & $8-7$ \\
\hline 12 & $10-10-10$ & $10-8-8$ & 7-6-10 & & & & & & & & $10-5$ \\
\hline 13 & 7-7-7 & 7-7-7 & 7-7-7 & & & & & & & & $8-7$ \\
\hline 14 & $10-10-10$ & $10-10-10$ & 9-9-9 & & & & & & & & 9-9 \\
\hline 15 & $10-10-9$ & $10-10-9$ & 8-8-8 & & & & & & & & $10-9$ \\
\hline 16 & 6-3-8 & 6-8-8 & $7-8-8$ & & & & & & & & $8-7$ \\
\hline 17 & $9-10-10$ & $9-9-10$ & 8-10-10 & & & & & & & & $10-6$ \\
\hline 18 & $7-5-6$ & 7-7-7 & 7-7-7 & & & & & & & & $7-7$ \\
\hline 19 & $7-6-7$ & $7-8-8$ & $9-8-8$ & & & & & & & & $9-5$ \\
\hline 20 & $9-5-10$ & $9-9-10$ & $8-7-9$ & & & & & & & & $8-8$ \\
\hline 21 & $7-8-6$ & 8-9-9 & 9-9-9 & & & & & & & & $8-7$ \\
\hline 22 & 8-5-8 & $10-8-7$ & $10-10-9$ & & & & & & & & $10-6$ \\
\hline 23 & $7-6-7$ & 8-8-7 & 8-8-8 & & & & & & & & $9-8$ \\
\hline 24 & $8-7-7$ & $6-6-7$ & $8-8-7$ & & & & & & & & $8-8$ \\
\hline 25 & 8-7-9 & 7-7-8 & $9-8-8$ & & & & & & & & $9-5$ \\
\hline 26 & $6-6-7$ & 7-7-7 & 7-8-7 & & & & & & & & $7-7$ \\
\hline 27 & $6-6-7$ & 6-6-7 & 7-7-7 & & & & & & & & 8- 6 \\
\hline
\end{tabular}

Fonte: Elaborada pelos autores.

Notas: (a) Do dia 1 ao dia 10 são exibidas as respostas das perguntas 1, 2 e 3, na coluna final são indicadas as respostas das perguntas 4 e 5. (b) Os valores se situam entre: 1 (extremamente infeliz) e 10 (extremamente feliz).

Em suma, os participantes avaliaram o período de estadia com uma média de 8,5 e indicaram que no momento da última resposta (cinco dias após 
o check-out) sentiam-se menos satisfeitos do que no momento da última resposta concedida ainda no resort (média 7,04), resultado este que já era esperado, dado que o período de hospedagem corresponde a um momento de férias, sendo que cinco dias após o check-out eles provavelmente já teriam voltado para suas rotinas de trabalho. Conclusões semelhantes foram elucidadas por Kemp, Burt e Furneaux (2008), os quais acreditam que esse comportamento se efetive pelo fato de os participantes terem ficado mais felizes em suas férias do que em suas vidas cotidianas.

Posteriormente a esta primeira análise, buscou-se avaliar a regra de pico-fim momentâneo, sendo sua estatística descritiva apresentada na Tabela 2.

Tabela2 Mensurações do pico-fim momentâneo

\begin{tabular}{l|r|r}
\hline Avaliação & Média & Desvio padrão \\
\hline Pico-fim momentâneo & 8,36 & 0,14 \\
\hline
\end{tabular}

Fonte: Elaborada pelo autor.

Observando a média das respostas, verifica-se que o pico-fim momentâneo exibiu uma média de 8,36 nas respostas, permitindo que antecipadamente se possa conjecturar que os picos de satisfação momentâneos são relevantes para a avaliação retrospectiva do evento. Esse resultado é corroborado já que os hóspedes do hotel ao indicarem sua satisfação geral com relação à estadia atingiram uma média de 8,5. Tal achado vai ao encontro com os apontados por Kemp, Burt e Furneaux (2008), os quais verificaram que no pico-fim as médias eram próximas às da avaliação geral do evento (pergunta 4), ratificando a teoria de que a avaliação retrospectiva, efetivamente, dá maior ênfase às sensações médias dos picos de satisfação e do momento imediatamente anterior ao fim da experiência (Fredrickson, 2000).

Mas, mesmo tendo essas percepções iniciais, são necessárias maiores elucidações. Assim, estima-se uma correlação entre o pico-fim momentâneo e a satisfação geral com a estadia (pergunta 4), buscando identificar se essa mensuração é bom previsor para a avaliação final da hospedagem estima-se uma correlação entre o pico-fim momentâneo e a satisfação final com a estadia.

O resultado revela que a associação entre a satisfação geral com a hospedagem e o pico-fim momentâneo é de 0,691, significativo a um nível de $1 \%$, o que ratifica as descrições já realizadas na estatística descritiva de que o pico-fim momentâneo pode ser um bom previsor para a satisfação final. 
De mesmo modo, com a estimação de uma regressão linear simples entre essas duas variáveis (coeficiente 0,747, significância. 0,000), corrobora-se a influência do pico-fim momentâneo para a consolidação da avaliação final. Ademais, tais evidências corroboram com parte da regra do pico-fim, segundo a qual a avaliação retrospectiva de um evento é influenciada pela sensação média do pico de satisfação (Redelmeier; Katz; Kahneman, 2003), confirmando também que a memória acaba por sobressair às lembranças mais significativas do evento (Kundera, 1991), já sendo este um indício de negligência com relação ao tempo.

Para testar se o tempo de permanência do hóspede no hotel teria influência na avaliação final de sua estadia, foi estimada a correlação entre o tempo de permanência no hotel e a avaliação final. O resultado revelou que não há associação entre o tempo de permanência no hotel e a avaliação final (sig. 0,675). Observando a Tabela 1, isso já era esperado, pois um hóspede que usufruiu um período de 10 dias no resort exibiu uma avaliação final com relação à hospedagem igual a hóspedes que desfrutaram apenas de quatro dias de hospedagem, ou seja, o tempo não é um fator preponderante que influencia a avaliação retrospectiva geral de um evento. Tal resultado já é amplamente aceito na literatura, podendo ser citado os trabalhos de Kahneman et al. (1993); Langer, Sarin e Weber (2000); Redelmeier e Kahneman (1996).

Mas, para aprofundar os resultados em relação a esse aspecto, bem como a influência do pico e do fim na avaliação final, foi rodada uma regressão linear múltipla tendo como variável dependente a satisfação geral, e como variáveis independentes, o pico, o fim e o tempo de hospedagem. A Tabela 3 evidencia os resultados referentes a essa estimação.

Tabela 3 Regressão da avaliação final da hospedagem com relação o pico, o fim e o tempo de hospedagem

\begin{tabular}{lrrrr}
\hline & Coeficiente & Std. Erro & t & Significância \\
\hline Constante & 1,847 & 1,375 & 1,343 & 0,192 \\
\hline Pico & 0,660 & 0,172 & 3,827 & 0,001 \\
\hline Fim & 0,171 & 0,162 & 1,058 & 0,301 \\
\hline Tempo & $-0,084$ & 0,078 & $-1,082$ & 0,290 \\
\hline R-quadrado & 0,457 & & & \\
\hline Teste F & 8,578 & & & \\
\hline Sig. & 0,000 & & & \\
\hline
\end{tabular}

Fonte: Elaborada pelos autores. 
Observando os resultados da regressão percebe-se que as variáveis independentes explicam, aproximadamente, $45 \%$ da variável dependente, dado o R-quadrado ter sido de 0,45 . Além disso, destaca-que que o teste $\mathrm{F}$ mostrou-se significativo (valor 8,578, sig. 0,000 ), revelando que o modelo é significativo como um todo. A partir disso, explorando os coeficientes da regressão e sua significância, evidencia-se que apenas o pico de satisfação apresentou-se significativo $(0,001)$, indicando este como determinante da satisfação geral. Por outro lado, o fim, ou seja, a última avaliação realizada pelos hóspedes não demonstrou impacto na satisfação geral.

Com isso, não é possível confirmar a regra do pico-fim, pois para isso o fim também deveria ser um preditor estatisticamente significativo para a satisfação geral. Resultados semelhantes foram identificados por Kemp, Burt e Furneaux (2008), os quais, numa avaliação de satisfação com férias, não confirmaram a regra do pico-fim. Desse modo, destaca-se apenas que a avaliação retrospectiva dos hóspedes do resort foi influenciada pelos picos de maior satisfação. Kundera (1991) já havia enfatizado esse ponto, argumentando que a satisfação com um evento é determinada por picos de satisfação e não pela experiência como um todo.

Considerando o tempo de hospedagem, confirma-se que este não é um bom preditor para a satisfação geral (sig. 0,290), ou seja, ratifica-se a negligência com relação ao tempo em avaliações retrospectivas. Esse resultado é amplamente aceito na literatura (Fredrickson, 2000; Fredrickson; Kahneman, 1993), e as evidências aqui apresentadas contribuem para consolidação de tal teoria num ambiente real, já que a maior parte dos estudos aponta esse desvio da racionalidade em ambientes experimentais manipulados.

\section{Considerações finais}

Dada a importância e incipiência de estudos na área, principalmente em contexto brasileiro, esta pesquisa teve como objetivo avaliar, em um ambiente natural, a regra do pico-fim e da negligência com relação ao tempo, tendo como público-alvo hóspedes de um resort em Florianópolis. Os principais resultados apontam que a hipótese do pico-fim não pode ser completamente ratificada, pois apenas o pico mostrou-se um bom preditor da avaliação final. Por outro lado, o pico-fim momentâneo pode ser considerado um preditor importante na avaliação retrospectiva de um evento. 
Em relação à negligência relativa ao tempo, parece haver uma inclinação da literatura a aceitar a hipótese de que o tempo de permanência não prediz a satisfação final com o evento, tendo os resultados aqui apresentados também corroborado esta conclusão. Assim, o número de dias passados no hotel não foi uma variável determinante para a avaliação retrospectiva de sua estadia.

Ratificando esses resultados identificados na parte inicial da análise, as regressões apontaram que as mensurações do pico-fim momentâneo, bem como o pico, influenciam significativamente na avaliação retrospectiva do evento, já o fim não revelou relevância para satisfação final, não podendo assim a teoria ser aqui completamente confirmada. Por outro lado, e bem como já salientado, os dias de permanência não demonstram estatisticamente nenhuma relação com a avaliação final, corroborando estudos anteriores.

Esses resultados contribuem para a consolidação de uma teoria ainda não estabelecido, já que não há congruência entre os autores sobre os melhores preditores para a avaliação retrospectiva. Eles contribuem, também, no sentido de incentivar novos estudos na área, enaltecendo tanto essa teoria quanto a economia comportamental como um todo.

\section{Referências}

ARIELY, D.; CARMON, Z. Summary assessment of experiences: The whole is different from the sum of its parts. In: LOEWENSTEIN, G.; READ, D.; BAUMEISTER, R. F. (Ed.). Time and decision: economic and psychological perspectives on intertemporal choice. New York: Russell Sage Foundation, 2003. p. 323-350.

CHRISTMAN, S. D.; PROPPER, R. E.; BROWN, T. J. Increased interhemispheric interaction is associated with earlier offset of childhood amnesia. Neuropsychology, v. 20, p. 336-345, 2006.

DO, A. M.; RUPERT, V.; WOLFORD, G. Evaluations of pleasurable experiences: The peakend rule. Psychonomic Bulletin \& Review, v. 15, n. 1, p. 96-98, 2008.

FREDRICKSON, B. L. Extracting meaning from past affective experiences: The importance of peaks, ends, and specific emotions. Cognition and Emotion, v. 14, p. 577-606, 2000.

GENG, X.; CHEN, Z.; LAM, W.; ZHENG, Q. Hedonic evaluation over short and long retention intervals: The mechanism of the peak-end rule. Journal of Behavioral Decision Making, v. 26, n. 3, p. 225-236, 2013.

KAHNEMAN, D. Rápido e devagar duas formas de pensar. Rio de Janeiro: Objetiva, 2012.

KAHNEMAN, D. et al. When more pain is preferred to less: Adding a better end. Psychol. Sci., v. 4, p. 401-405, 1993. 
KAHNEMAN, D; TVERSKY, A. Prospect Theory: An analysis of decision under risk. Econometrica, v. 47, n. 2, p. 263-292, 1979.

KEMP, S.; BURT, C. D. B.; FURNEAUX, L. A test of the peakend rule with extended autobiographical events. Memory \& Cognition, v. 36, n. 1, p. 138, 2008.

KENT, G. Memory of dental pain. Pain, v. 21, p. 187-194, 1985.

KUNDERA, M. Imortallity. New York: Grove Press, 1991.

LANGER, T.; SARIN, R.; WEBER, M. The retrospective evaluation of payment sequences: duration neglect and peak-and-end-effects. In: UNIVERSITY OF MANNHEIM. Sonderforschungsbereich 504: Rationalitatskonzepte, Entscheidungsverhalten und ökonomische modellierung. Mannheim, 2000.

LIST, J. A. Field Experiments: a bridge between lab and naturally occurring data. The B. E. Journal of Economic Analysis and Policy, v. 6, n. 2, 2006.

RACHMAN, S.; EYRL, K. Predicting and remembering recurrent pain. Behaviour Research and Therapy, v. 27, p. 621-635, 1989.

REDELMEIER, D. A.; KAHNEMAN, D. Patients' memories of painful medical treatments: real-time and retrospective evaluations of two minimally invasive procedures. Pain, v. 66, p. 3-8, 1996.

REDELMEIER, D. A.; KATZ, J.; KAHNEMAN, D. Memories of colonoscopy: A randomized trial. Pain, v. 104, p. 187-194, 2003.

STRATTEN, S.; KRAMER, A. Unselling: The new costumer experience. [S.1.]: Wiley, 2014.

THOMAS, D. L.; DIENER, E. Memory accuracy in the recall of emotions. Journal of Personality and Social Psychology, v. 59, p. 291-297, 1990.

ZAJCHOWSKI, Chris AB; SCHWAB, Keri A.; DUSTIN, Daniel L. The experiencing self and the remembering self: Implications for leisure science. Leisure Sciences, v. 39, n. 6, p. 561-568, 2017.

\section{Sobre os autores}

Guilherme Faria Alano-guilhermefalano@hotmail.com

Universidade Federal de Santa Catarina, Florianópolis, Santa Catarina, Brasil.

ORCID: https://orcid.org/0000-0003-0613-1477.

Newton Carneiro Affonso Da Costa Junior-ncacjr@gmail.com

Escola de Negócios da Pontifícia Universidade Católica do Paraná, Curitiba, Paraná, Brasil.

ORCID: https://orcid.org/0000-0001-7723-2676.

Jéssica Pulino Campara-jecampara@hotmail.com

Universidade Federal de Santa Catarina, Florianópolis, Santa Catarina, Brasil.

ORCID: https://orcid.org/0000-0002-0283-9243.

\section{Sobre 0 artigo}

Recebido em 17 de julho de 2017. Aprovado em 6 de dezembro de 2017. 